\title{
Physical activity and breast cancer: Results of a focus group to devise novel exercise interventions for women with breast cancer
}

\author{
Jenna Smith-Turchyn*1, Julie Richardson' ${ }^{1}$, Richard Tozer ${ }^{2}$, Lehana Thabane ${ }^{3}$, Margaret McNeely ${ }^{4}$ \\ ${ }^{1}$ McMaster University, School of Rehabilitation Science, Hamilton, ON, Canada \\ ${ }^{2}$ Juravinski Cancer Centre, Department of Oncology, Hamilton, ON, Canada \\ ${ }^{3}$ McMaster University, Department of Health Research Methods, Evidence and Impact, St. Joseph's Healthcare Hamilton, \\ Hamilton, ON, Canada \\ ${ }^{4}$ School of Rehabilitation Medicine, University of Alberta, Edmonton, AB, Canada
}

Received: October 10, 2017

Accepted: December 10, 2017 Online Published: December 15, 2017

DOI: $10.5430 /$ cns.v6n2p39

URL: https://doi.org/10.5430/cns.v6n2p39

\begin{abstract}
Objective: To determine, from the diverse perspective of vested members of the health care team, novel exercise intervention strategies to implement within the cancer care institution in order to overcome barriers to exercise participation and promotion for women with breast cancer (BC).

Methods: Design: Qualitative descriptive study. Setting: Cancer care institution. Participants: Health care professionals (HCPs) who work with women with BC. Intervention: A focus group was used to answer the research question. A moderator guided the focus group using a semi-structured script. Measurements: The focus group was recorded and transcribed. The transcript was coded independently using topic and analytical coding.

Results: Three main issues came forth during analysis. These included a lack of (1) exercise programming and equipment available within the cancer care institution (2) communication with rehabilitation professionals, and (3) effective exercise education strategies available for patients with BC. Specific strategies were suggested to overcome each issue. Limitations: As purposeful sampling was used for recruitment, it is possible that participants agreed to be in this study because they had positive views on the need to incorporate exercise more effectively into practice.

Conclusions: To our knowledge this is the first study to include a multidisciplinary team to come to a consensus on a knowledge translation exercise strategy. Findings show that future exercise interventions should implement active interventions within the cancer institution, include rehabilitation professionals as part of the health care team, and use technology to educate patients.
\end{abstract}

Key Words: Breast neoplasms, Exercise, Translational medical research, Qualitative research

\section{INTRODUCTION}

Breast cancer (BC) is the most frequently diagnosed cancer in North American women. ${ }^{[1]}$ The prognosis for this disease has improved significantly in the last decade, with a five year survival rate around $90 \%{ }^{[1]}$ However, women with BC live with many physical and psychological side effects for many years after their cancer treatments have ended. ${ }^{[2-4]}$ These side effects manifest into various functional limitations. ${ }^{[2-4]}$

\footnotetext{
*Correspondence: Jenna Smith-Turchyn; Email: smithjf@ mcmaster.ca; Address: McMaster University, School of Rehabilitation Science, 1400 Main Street W., Hamilton, ON, Canada.
} 
Moderate intensity exercise of various forms has been shown to mitigate many of these side effects, ${ }^{[5-16]}$ however, it has been found that less than $30 \%$ of the population takes part in the recommended level of exercise. ${ }^{[17,18]}$

Barriers to exercise participation for women with $\mathrm{BC}$ have been studied thoroughly in the literature. ${ }^{[17,19-21]}$ Results have found both individual factors and educational factors to limit participation. ${ }^{[17]}$ Individual factors include physical symptoms and fatigue, whereas educational factors relate to a lack of general knowledge on the need to stay physically active during and after treatment, proper exercise prescriptions, and available exercise programs. ${ }^{[17]}$ One of the most startling findings is that there is a lack of education being provided to patients on the benefits of exercise during and after BC treatment. ${ }^{[17]}$

Barriers to exercise promotion from the perspective of the health care professional (HCP) are not as well documented in the literature. However, recent research in Ontario has found that barriers at the institutional level, HCP level, and patient level may all contribute to a lack of exercise promotion. ${ }^{[22]}$ For example, institutionally a lack of time with each patient, a lack of defined role for who should be discussing exercise, and a lack of funding for the inclusion of rehabilitation professionals and exercise programs were stated barriers to exercise promotion. ${ }^{[22]}$ Professionally, HCPs commonly described a lack of their own specific exercise knowledge and a vast number of competing priorities needed to discuss with their patients as barriers to exercise promotion. ${ }^{[22]}$ Finally, professionals also perceived patients with $\mathrm{BC}$ as having poor attitudes towards exercise, lacking accessibility to exercise resources, and having complex medical needs as patient barriers to promoting the recommended levels of exercise. ${ }^{[22]}$ Both the patient and the HCP reported that barriers to exercise participation and promotion respectively have limited the implementation of this effective, low-cost, low-risk management strategy.

Due to the gap between the research evidence, supporting the use of regular, moderate intensity exercise to manage the side effects of cancer treatment, and actual clinical practice, there is growing demand to develop novel knowledge translation exercise strategies and to incorporate exercise into the regular cancer care continuum. With evidenced based guidelines from organizations such as the American Congress of Sports Medicine ${ }^{[10]}$ and Cancer Care Ontario ${ }^{[23]}$ summarizing the benefit of and need for exercise interventions, future work is needed to implement these strategies effectively.

The purpose of this qualitative study is to determine, from the diverse perspective of vested members of the health care team, novel exercise intervention strategies to implement within the cancer care institution to overcome the described barriers to exercise participation and promotion for women with BC.

\section{METHODS}

\subsection{Study design}

A qualitative descriptive design using a focus group to collect data from HCPs who treat women with BC was used in this study. Qualitative descriptive studies are the method of choice when clear descriptions of a problem or event are desired. ${ }^{[24]}$ In this study we sought to describe strategies to overcome the barriers to exercise implementation, therefore a qualitative descriptive study was the method of choice. Focus groups are a technique that involves the use of in-depth group interviews with purposively recruited participants who have expertise on a given topic. ${ }^{[2,26]}$ This methodology has been found to be a useful vehicle for involving users in care management and strategy development techniques. ${ }^{[27]}$ The Hamilton Integrated Research Ethics Board approved this study (\#0552).

\subsection{Participants}

Participants included in this study were English-speaking HCPs working with women with BC in southwestern Ontario. We sought to recruit between six to ten participants for this focus group as this number has been shown in the literature to be a manageable number to gain a variety of perspectives while still allowing all participants to engage in the discussion. ${ }^{[25,28,29]}$ In order to answer the study question participants were recruited from a multidisciplinary team of HCPs. Health professionals included oncologists, nurses, dieticians, and physiotherapists. Participants were recruited through a combination of purposive and snowball sampling. Firstly a recruitment email was sent to members of the breast disease site team at the Juravinski Cancer Centre (JCC) in Hamilton, Ontario. This team includes oncologists, surgeons, primary care nurses, social workers, and dieticians. Individuals from the JCC who agreed to participate in the focus group also suggested other potential participants for the study and these individuals were sent a personalized email to request their participation. All participants were within a similar age range (40-65 years) and had similar socio-economic characteristics and educational levels (master's level or greater). Similarity in these characteristics is suggested in the literature to ensure all members of a focus group are comfortable talking to each other and sharing ideas. ${ }^{[25,28,30]}$ Participants had met the primary researcher (JST) during a previous study and were aware that the moderators (JST \& JR) were physiotherapists with an interest in promoting exercise in women with BC. 


\subsection{Data collection}

Focus group data was collected in November 2015 in a private conference room at the JCC. Participants were offered a light breakfast during the session. The focus group was moderated by the first author (JST), trained in qualitative research methods, with assistance from another researcher (JR). The moderator guided the focus group using a semi-structured script while the assistant made field notes on participant's moods and gestures and summarized major discussion points on a flip chart, giving the participants an opportunity to clarify anything they felt was missing or misunderstood by the research team. To begin, the participants were asked to provide written informed consent. They were then given a brief introduction to the literature on the benefits of exercise for women with $\mathrm{BC}$, as well as the researched barriers to exercise participation and promotion from both the patients and HCPs perspective. After each of these topics the participant's were given time to ask clarification questions and to voice their opinions about the research findings. Following this the participants were asked to suggest exercise intervention strategies based on their professional needs, the institutions needs in order to provide quality care, and the barriers discussed. Open-ended questions were used initially to facilitate the group discussion and ease the participants into the discussion. ${ }^{[31]}$ Additional probing questions were used when necessary to ensure comprehension or to elicit more information. Discussion was facilitated until saturation of the responses between participants was evident. The focus group lasted approximately one hour and was audio recorded using two recorders.

\subsection{Data analysis}

Following the focus group the audio recording was transcribed verbatim with all identifiers removed. The transcript was then checked for accuracy and completeness by the moderator. Two researchers (JST and JR) simultaneously coded the transcripts independently prior to discussing results. Content analysis used topic and analytical coding. Topic coding refers to labeling the text according to its subject. ${ }^{[32]}$ This is often the initial stage of identification and labeling. ${ }^{[33]}$ Analytical coding is coding that comes from interpretation and reflection on meaning. ${ }^{[32]}$ This is often the second stage of coding, used to refine and interpret meaning in the transcripts. ${ }^{[33]}$ In this project, topic coding dominated, especially early on, and was the first step in allowing more interpretive work using analytical coding. After coding the transcript, the researchers met to discuss the emerging themes and develop a final coding scheme. The transcript and field notes were then uploaded into NVivo v10.2 (qualitative analysis software) and the coded data was aggregated into nodes and grouped into categories based on the patterns that arose from the data. The coded data was reviewed periodically in order to ensure comprehensive analysis. ${ }^{[32]}$ Saturation of themes was ensured between various professions and participants during analysis. To determine saturation authors ensured that no new themes were developed for continued analysis of information. Discussions between researchers occurred periodically during transcription to consider how the developing codes addressed the research question. Memos were completed throughout the coding process to track changes in processes and analytical momentum, determine the importance of specific codes, associations between codes or categories, and questions that arose from the coded data. ${ }^{[32,33]}$ Frequencies and percentages were calculated for demographic data. The results were summarized and sent to participants for member checking and feedback after analysis was completed.

\section{RESULTS}

Ten participants agreed to be in the study. One participant had to cancel the day of the focus group due to family illness, leaving nine participants. No other individuals were present. The participants varied in health profession and gender. See Table 1 for participant characteristics.

Table 1. Participant characteristics

\begin{tabular}{ll}
\hline Characteristic & Number \\
\hline Health Professional: & 2 \\
- Medical Oncologist & 1 \\
- Radiation Oncologist & 1 \\
- General Practitioner in Oncology & 1 \\
- Nurse Practitioner & 1 \\
- Primary Care Nurse & 2 \\
- Physiotherapist & 1 \\
- Dietician & \\
Gender: & 2 \\
- Male & 7 \\
- Female &
\end{tabular}

After discussing the researched barriers to exercise participation and exercise promotion for patients and HCPs, three major challenges currently present for this population were identified in the discussion and came forth during analysis. These challenges were grouped into three categories: (1) a lack of exercise programming and exercise equipment available within the cancer care institution, (2) a lack of communication with rehabilitation professionals within the institution and externally, and (3) a lack of effective education strategies available for patients with $\mathrm{BC}$ and their families. The intervention strategies suggested to address each of these challenges are described below. 
Table 2. Quotations representing suggested exercise interventions for main challenges described

\begin{tabular}{|c|c|}
\hline Category (Challenge) & Quotation \\
\hline $\begin{array}{l}\text { Lack of exercise } \\
\text { programming and } \\
\text { equipment available } \\
\text { within the cancer care } \\
\text { institution in Ontario }\end{array}$ & $\begin{array}{l}\text { - "I want a meditation room and... an exercise room in the chemo suite so when they (patients) are waiting } \\
\text { for their chemo appointment they can either go into the meditation room and have either reflexology or } \\
\text { meditate or whatever and then the other room if they wanted to have, you know, go on the treadmill or } \\
\text { whatever or do some weights, and have someone there supervising them. So that's my utopia." } \\
\text { - "I'm thinking something a lot simpler...it's just a walking track that is metered out in the cancer...centre } \\
\text { over to the hospital. You could have a little book that says OK...how many steps are you going to do...and } \\
\text { we'll put a little guidance out there (for the patients)." }\end{array}$ \\
\hline $\begin{array}{l}\text { Lack of communication } \\
\text { with rehabilitation } \\
\text { resources }\end{array}$ & $\begin{array}{l}\text { - "You know, just to have somebody...just even have a go to (rehabilitation person), we don't even have a } \\
\text { "go to" person. It's very, very dispersed." } \\
\text { - “... a really good example is yesterday... a patient of mine was being seen and was having their file } \\
\text { reviewed. They had bone mets and basically the recommendation is that she probably needs immediate } \\
\text { surgery and should have, what's it, feather touch. So, I'm looking at this... and we don't even know what this } \\
\text { means...what are we supposed to be telling the patient. And there's no resource, who do you go to?" } \\
\text { - "So, ideally I think every patient should have the right to be screened by a physiotherapist or kinesiologist } \\
\text { to determine whether they are safe to exercise. A pre-determined level of exercise should be made... are you } \\
\text { a never exerciser, an exerciser, you know, how much, etc. Then patients should have the opportunity to be } \\
\text { triaged according to their needs...whether they are OK to exercise or might need some guidance from an } \\
\text { exercise program.". }\end{array}$ \\
\hline $\begin{array}{l}\text { Lack of effective } \\
\text { exercise education } \\
\text { strategies available for } \\
\text { patients with breast } \\
\text { cancer and their families }\end{array}$ & $\begin{array}{l}\text { - "I was wondering about the computer screen that you are supposed to go through in the waiting room and } \\
\text { fill in ...perhaps there could be something related to exercise that is actually an exercise algorithm where } \\
\text { you are getting what the person is all about and what they would prefer in terms of the pathway to exercise, } \\
\text { whether it is during active treatment or afterwards." } \\
\text { - "One more thing about the waiting rooms...just as a patient... maybe instead of 'life of the Kardashian's, } \\
\text { showing up on the TV...it perhaps could be something correlated to exercise or maybe something } \\
\text { personalized like everyone gets a little ipad when they come in and you know, they could select the channel } \\
\text { that they want, but the channels are related to health promotion as oppose to reality TV." } \\
\text { - "I would love for our breast cancer patients to have a little hand held device and look at some video on how } \\
\text { to increase the mobilization of their shoulder while they are sitting around, maybe at their radiation } \\
\text { planning point..." }\end{array}$ \\
\hline
\end{tabular}

\subsection{Category 1: There is currently a lack of exercise pro- gramming and equipment available within the can- cer care institution in Ontario}

There was mutual agreement from all participants that an on-site exercise program was needed for this patient population. This was suggested in a variety of ways, from exercise equipment being available within waiting rooms, to having designated exercise rooms within the cancer centre, or having a walking track throughout the hospital. Having an exercise program available on site was thought to have the potential to decrease patient accessibility problems (with regard to costs of existing programs and transportation barriers) and increase exercise awareness, by having patients and their families see others in similar situations participating safely in exercise. See Table 2 for specific examples of suggestions for this category.

\subsection{Category 2: There is currently a lack of communica- tion with rehabilitation professionals}

Three participants described situations where they needed information from rehabilitation resources, and sought out resources for advice on rehabilitation within the institution, but could not find the information they needed or did not know who to talk to within or outside of the cancer centre. This resulted in them not knowing what to tell the patient about their current problem. All participants agreed, that having a rehabilitation professional on site would allow them to give their patients better information to support their rehabilitation needs. This professional could be used as an individual referral for the patient or as a support/information service for the HCPs. Suggested ways that a rehabilitation professional could be used within the institution varied from having physiotherapists perform pre-treatment functional assessments 
and triaging patients based on their needs, to providing general education on physical activity and exercise, or providing exercise interventions on site. Table 2 gives specific examples of suggested strategies for this category.

\subsection{Category 3: There is currently a lack of effective exercise education strategies available for patients with $\mathrm{BC}$ and their families}

All participants agreed that more effective educational strategies on the benefits of exercise during and after BC treatment are needed for patients and their families within the institution. If effectively implemented, participants thought that patients would be less apprehensive of their ability to exercise during treatment and their families would be more encouraging of maintaining physical activity levels and less fearful of safety concerns. The majority of focus group participants thought this should be done through the use of technology. There was a variety of suggested ways to implement educational interventions using technology, including (1) using computer programs currently available within patient waiting rooms, (2) creating and showing educational programs on television screens currently in patient waiting rooms, and (3) providing patients with activity trackers to make them aware of their own physical activity levels compared to the recommended guidelines. See Table 2 for examples of these educational strategies.

\subsection{Other considerations}

While participants suggested these exercise intervention strategies, they also voiced many points that need consideration before successful implementation would occur. This included the need to specify the disease severity of patients who were provided exercise interventions; to make the interventions accessible for all patients with $\mathrm{BC}$ who want to participate within the cancer centre (regardless of socioeconomic status or education level); to make the interventions financially manageable for the patient and the institution; to consider the psychological aspects of the disease and how this may affect successful behavioural change; and the need to include "important others" (families and the patients' health care team) of patients within the provided interventions.

\section{PHYSICAL ACTIVITY \& BREAST CANCER: FOCUS GROUP SUMMARY}
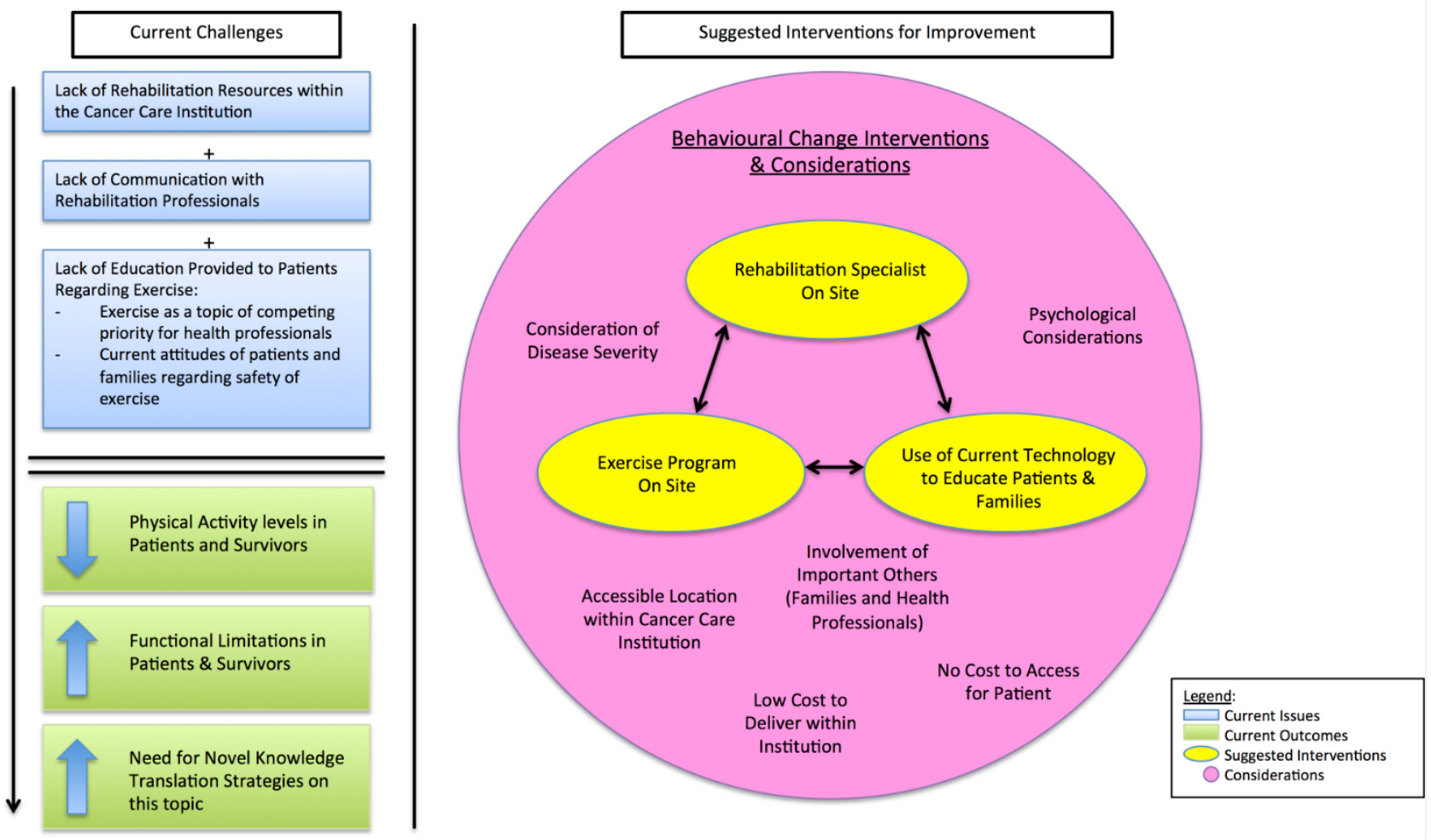

Figure 1. Interventions to overcome exercise challenges

Figure 1 summarizes the results of the focus group. The algorithm on the left side of the figure describes the main challenges related to exercise and rehabilitation. These chal- lenges result in decreased physical activity levels in patients and survivors, which result in adverse physical side effects and functional limitations during and after their BC treat- 
ment. The circle on the right side of the figure summarizes the suggested interventions to overcome these challenges. The three main strategies (having both rehabilitation specialists and exercise interventions on site, together with using current technology to educate patients) are presented in the central yellow ovals, while special considerations are represented outside of these central strategies, but are shown to be necessary in each strategy for successful behavioural change within this population.

\section{Discussion}

The aim of this study was to determine novel exercise intervention strategies to implement within the cancer care institution in Ontario in order to overcome the described barriers to exercise participation and promotion for women with BC. To our knowledge this is the first study to include a multidisciplinary team of HCPs in the development of novel exercise strategies to implement for this population. The depth of research over the past decade on the benefits of exercise for women with $\mathrm{BC}$ both during and after treatment has grown substantially. There is convincing evidence of symptom management at various points throughout the cancer trajectory and decreased recurrence rates post treatment. ${ }^{[3,8-14,34]}$ Because of these demonstrated benefits, it is recommended that exercise interventions be incorporated at various points during the patients' care. ${ }^{[35]}$ This includes pre-treatment, at various points during active treatment, and post treatment. ${ }^{[35]}$ Having the patient monitored at various points by a rehabilitation professional, has been shown to prevent long-term side effects (such as lymphedema incidence and upper extremity morbidity) and improve health care costs related to these side effects, therefore benefiting all stakeholders. ${ }^{[34-39]}$

However, cancer rehabilitation programs remain the exception, rather than the norm for individuals with $\mathrm{BC}$ in Ontario. ${ }^{[40]}$ There is now a need for research that pertains to the development of novel and effective delivery models to change patient behaviour, improve exercise adherence, and translate the knowledge into clinical practice at the systems level. ${ }^{[40]}$ Research projects, such as this study, which incorporate stakeholders in the development of these needed interventions, is one approach to ensure the collegial support of various HCPs within the institution to drive these programs. ${ }^{[40,41]}$ With the support of various stakeholders within institutions the sustainability and effectiveness of promoting behavioural change is likely to be enhanced.

Numerous implementation strategies were suggested within this research study to engage patients with $\mathrm{BC}$ in exercise. An important consideration is to determine who should be providing this intervention for this population. Certain as- pects of scope of practice do overlap for HCPs such as primary care nurses, physiotherapists, and kinesiologists. The necessary skills for providing these intervention strategies include: (1) adequate knowledge of the disease process, treatments given and physiological responses of treatment, (2) adequate knowledge on exercise parameters and the physiological responses of exercise, (3) adequate knowledge of safe practices in regards to exercise and emergency response skills, and (4) the ability to accommodate/tailor exercise programs to suite the needs of ill populations. Based on these skills, we propose that the best suited to take on this role be a rehabilitation professional who is an exercise specialists trained in working with people with chronic conditions. This professional could also act as a facilitator to train other professions on how to work effectively with this population on this intervention. ${ }^{[42,43]}$

While support was evident within this focus group for the implementation of exercise interventions within the cancer centre, it came up repeatedly that a major focus must also be on producing successful and sustainable behaviour change with this population and that research must include an assessment of program sustainability within the institution. In order to do this, the literature highlights the need for theory-based interventions in $\mathrm{BC}$ rehabilitation. ${ }^{[4,45]}$ Specifically, in order for behavioural change to happen for women with BC, evidence shows a person's attitudes and subjective norms (ideas of important others such as family, friends, fellow patients, and the health care team) have high levels of association with an individual's intention to exercise, and therefore actual exercise behaviour. ${ }^{[45]}$ These concepts were all represented in the suggestions of the focus group members, which shows consistency with the current theory based literature on this topic. Therefore, while being implemented, the suggested exercise interventions must take theoretical considerations into account in order to ensure sustainable behaviour change for this patient group.

\section{Limitations}

The results of this study should be interpreted with an understanding of its limitations. One limitation of this study was that all participants in this study are employed in one area of Ontario. Therefore, the generalizability of these results to various areas within and outside of Canada should be within the context under consideration. However, this treatment centre is part of a larger regional treatment program which follows similar practice guidelines and has similar program funding allocations. Therefore, while certain details of these interventions may need to be adapted to specific settings, translation of the larger issues and ideas brought forth in this study can occur. Also, purposive sampling was used 
to recruit the participants to this study. It is possible that these participants agreed to be in this study because they had positive ideas on the current barriers to exercise for this population and understood the need to incorporate exercise more effectively into clinical practice.

\section{Conclusions}

In conclusion, this study was novel in that it brought together HCPs to discuss and suggest strategies to implement "real life" exercise interventions within institutions as part of the acute management for patients with BC to close the knowl- edge to practice gap. Findings show that future interventions should focus on implementing exercise interventions within the cancer care institution, including rehabilitation professionals as part of the team of HCPs who work with this patient population, and using technology to educate patients and families on the need to exercise during and after treatment. The next step is to design and implement these interventions and then to assess their effectiveness in overcoming the barriers to exercise for women with BC.

\section{CONFLICTS OF INTEREST DisClosure}

The authors declare they have no conflicts of interest.

\section{REFERENCES}

[1] Canadian Cancer Society's Advisory Committee on Cancer Statistics. Canadian Cancer Statistics 2015. Toronto, ON; 2015. Available from: https://www. cancer.ca/ /media/cancer.ca/CW/cancer\% 20 information/cancer $\% 20101 /$ Canadian $\% 20$ cancer $\% 20$ sta tistics/Canadian-Cancer-Statistics-2015-EN.pdf

[2] Shapiro SL, Lopez AM, Schwartz GE, et al. Quality of life and breast cancer: relationship to psychosocial variables. J Clin Psychol. 2001; 57(4): 501-19. PMid: 11255204. https://doi.org/10.1002/jc lp. 1026

[3] Cella D, Fallowfield LJ. Recognition and management of treatmentrelated side effects for breast cancer patients receiving adjuvant endocrine therapy. Breast Cancer Res Treat. 2009; 107: 167-180. PMid: 17876703. https://doi.org/10.1007/s10549-007-9548-1

[4] Ewertz M, Jensen AB. Late effects of breast cancer treatments and potentials for rehabilitation. Acta Oncol. 2011; 50: 187-93. PMid: 21231780. https://doi.org/10.3109/0284186X. 2010. 533190

[5] Cormie P, Pumpa K, Galvao D, et al. Is it safe and efficacious for women with lymphedema secondary to breast cancer to lift heavy weights during exercise: a randomized controlled trial. J Cancer Surviv. 2013; 7(3): 413-424. PMid: 23604998. https: //doi.org/10.1007/s11764-013-0284-8

[6] Pastakia K, Kumar S. Exercise parameters in the management of breast cancer: a systematic review of randomized controlled trials. Physiother Res Int. 2011; 16(4): 237-244. PMid: 21204162. https://doi.org/10.1002/pri.505

[7] Chan D, Lui L, So W. Effectiveness of exercise programmes on shoulder mobility and lymphedema after axillary lymph node dissection for breast cancer: systematic review. J Adv Nurs. 2010; 66(9): 1902-1914. PMid: 20626480.

[8] Bicego D, Brown K, Ruddick M, et al. Effects of exercise on quality of life in women living with breast cancer: a systematic review. Breast J. 2009; 15(1): 45-51. PMid: 19120381. https: //doi.org/10.1111/j.1524-4741.2008.00670.x

[9] McNeely M, Campbell K, Rowe B, et al. Effects of exercise on breast cancer patients and survivors: a systematic review and metaanalysis. CMAJ. 2009; 175(1): 34-41. PMid: 16818906. https: //doi.org/10.1503/cmaj.051073

[10] Schmitz KH, Courneya KS, Matthews C, et al. American College of Sports Medicine roundtable on exercise guidelines for cancer survivors. Med Sci Sports Exerc. 2010; 42(7): 1409-1426. PMid:
20559064. https://doi.org/10.1249/MSS.0b013e3181e0c1 12

[11] Courneya KS, Segal RJ, McKenzie DC. Effects of exercise during adjuvant chemotherapy on breast cancer outcomes. Med Sci Sports Exerc. 2014; 46(9): 1744-1751. PMid: 24633595. https: //doi.org/10.1249/MSS.0000000000000297

[12] McNeely M, Campbell K, Ospina M. Exercise interventions for upper-limb dysfunction due to breast cancer treatment. Cochrane $\mathrm{Db}$ Syst Rev. 2010; 16(6): CD005211. https://doi.org/10.1002/ 14651858.CD005211.pub2

[13] Zou LY, Yang L, He XL, et al. Effects of aerobic exercise on cancerrelated fatigue in breast cancer patients receiving chemotherapy: A meta-analysis. Tumour Biol. 2014; 35(6): 5659-5667. PMid: 24570186. https://doi.org/10.1007/s13277-014-1749-8

[14] Schmitz K, Ahmed R, Troxel A, et al. Weight lifting for women at risk of breast cancer-related lymphedema. A randomized trial. JAMA. 2010; 304(24): 2699-2705. PMid: 21148134. https ://doi .org/ 10.1001/jama.2010.1837

[15] Cramer H, Lange S, Klose P, et al. Yoga for breast cancer patients and survivors: A systematic review and meta-analysis. BMC Cancer. 2012; 18(12): 412. PMid: 22988934. https://doi .org/10.118 6/1471-2407-12-412

[16] Mustian KM, Palesh OG, Flecksteiner SA. Tai Chi Chuan for breast cancer survivors. Med Sport Sci. 2008; 52: 209-217. PMid: 18487900. https://doi.org/10.1159/000134301

[17] Fernandez S, Franklin J, Amlani N, et al. Physical activity and cancer: A cross-sectional study on the barriers and facilitators to exercise during cancer treatment. Canadian Oncology Nursing Journal. 2015; 25(1): 37-42. PMid: 26642493. https://doi .org/10.5737/23 6880762513742

[18] Courneya KS, Katzmarzyk PT, Bacon E. Physical activity and obesity in Canadian cancer survivors. Cancer. 2008; 112(11): 2475-82. PMid: 18428195. https://doi.org/10.1002/cncr. 23455

[19] Blaney JM, Lowe-Strong A, Rankin J, et al. The cancer rehabilitation journey: barriers to and facilitators of exercise among patients with cancer-related fatigue. Phys Ther. 2010; 90: 1135-47. PMid: 20558566. https://doi.org/10.2522/ptj. 20090278

[20] Sander AP, Wilson J, Izzo N, et al. Factors that affect decisions about physical activity and exercise in survivors of breast cancer: a qualitative study. Phys Ther. 2012; 92: 525-36. PMid: 22156026. https://doi.org/10.2522/ptj.20110115

[21] Brunet J, Taran S, Burke S, et al. A qualitative exploration of barriers and motivators to physical activity participation in women 
treated for breast cancer. Disabil Rehabil. 2013; 35(24): 2038-2045. PMid: 23772995. https ://doi.org/10.3109/09638288.2013. 802378

[22] Smith-Turchyn J, Richardson J, Tozer R, et al. Physical activity and breast cancer: A qualitative study on the barriers to and facilitators of exercise promotion from the perspective of health care professionals. Physiother Can. 2016; 68(4): 383-390. PMid: 27904238. https://doi.org/10.3138/ptc.2015-84

[23] Segal R, Zwaal C, Green E, et al. Exercise for people with cancer: A quality initiative of the program in evidence-based care. Cancer Care Ontario. 2015. Available from: https ://www. cancercare .on.ca/common/pages/UserFile.aspx?fileId=342807

[24] Sandelowski M. Focus on research methods: Whatever happened to qualitative description? Res Nurs Health. 2000; 23: 334-340. https ://doi .org/10.1002/1098-240X (200008) 23: 4<334: : AID-NUR9>3.0.CO;2-G

[25] Rabiee F. Focus-group interview and data analysis. Proceedings of the Nutrition Society. 2004; 63: 655-660. PMid: 15831139. https://doi.org/10.1079/PNS2004399

[26] Thomas L, MacMillian J, McColl E, et al. Comparison of focus group and individual interview methodology in examining patient satisfaction with nursing care. Social Science in Health. 1995; 1: 206-219.

[27] Basch C. Focus group interview: An under-utilised research technique for improving theory and practice in health education. Health Education Quarterly. 1987; 14: 411-418. PMid: 3319971. https : //doi.org/10.1177/109019818701400404

[28] Ontario Women's Health Network. Guide to Focus Groups. Toronto, ON: OWNH; 2009.

[29] Krueger RA, Casey MA. Focus groups: A practice guide for applied research. Thousand Oaks: Sage Publications; 2000. https: //doi.org/10.1037/10518-189

[30] Richardson CA, Rabiee F. "A Question of Access"—an exploration of the factors influencing the health of young males aged 15-19 living in Corby and their use of health care services. Health Education Journal. 2001; 60: 3-6. https://doi.org/10.1177/001789690106 000102

[31] Kreuger RA. Is it a focus group? Tips on how to tell. Journal of Wound, Ostomy and Continence Nursing. 2006; 33: 363-366. https://doi.org/10.1097/00152192-200607000-00003

[32] Richards L. Handling qualitative data: A practical guide. London, England: SAGE Publications Inc.; 2009.

[33] Blazely P. Qualitative data analysis: Practical strategies. London, England: SAGE Publications Inc.; 2013.

[34] Lahart IM, Metsios GS, Nevill AM, et al. Physical activity, risk of death and recurrence in breast cancer survivors: A systematic review and meta-analysis of epidemiological studies. Acta Oncol. 2015;
54(5): 635-654. PMid: 25752971. https://doi.org/10.3109/ 0284186X.2014.998275

[35] Stout N, Binkley JM, Schmitz KH, et al. A prospective surveillance model for rehabilitation for women with breast cancer. Cancer. 2012; $118(8$ Suppl): 2191-2200. PMid: 22488693. https: //doi.org/10.1002/cncr. 27476

[36] Hayes SC, Johansson K, Stout NL, et al. Upper-body morbidity after breast cancer: Incidence and evidence for evaluation, prevention, and management within a prospective surveillance model of care. Cancer. 2012; 118(8 Suppl): 2237-2249. PMid: 22488698. https://doi.org/10.1002/cncr.27467

[37] Stout N, Pfalzer LA, Springer B, et al. Breast cancer related lymphedema: Comparing direct costs of a prospective surveillance model and traditional model of care. Phys Ther. 2012; 92(1): 152-163. PMid: 21921254. https://doi.org/10.2522/ptj.20100167

[38] Silver JK. Cancer prehabilitation and its role in improving health outcomes and reducing health care costs. Semin Oncol Nurs. 2015; 31(1): 13-30. PMid: 25636392. https://doi.org/10.1016/j . soncn.2014.11.003

[39] Silver JK, Baima J, Newman R, et al. Cancer rehabilitation may improve function in survivors and decrease the economic burden of cancer to individuals and society. Work. 2013; 46(4): 455-472. PMid: 24125901.

[40] Santa Mina D, Alibhai SM, Matthew AG, et al. Exercise in clinical cancer care: A call to action and program development description. Curr Oncol. 2012; 19(3): 136-144. PMid: 22670103. https://doi.org/10.3747/co.19.912

[41] Ahmed S, Ware P, Visca R, et al. The prevention and management of chronic disease in primary care: Recommendations from a knowledge translation meeting. BMC Res Notes. 2015; 15(8): 571. PMid: 26471509. https ://doi .org/10.1186/s13104-015-1514-0

[42] Canadian Physiothearpy Association. Scope of Practice Briefing Note. Accessed 15 Jan 2016. Available from: https: //www . physiotherapy . ca/getmedia/e2541bbc-f95d-4d8 b-b689-98365bc4abbd/Scope-of-Practice_EN.pdf .aspx

[43] College of Physiotherapists of Ontario. Scope of Practice Resources. Accessed 15 Jan 2016. Available from: http://www. collegept. org/Resources\#ScopePractice

[44] Smith-Turchyn J, Richardson J. A critical review of the Theory of Planned Behaviour to predict and explain exercise behaviour in women with breast cancer. Critical Reviews in Physical and Rehabilitation Medicine. 2015; 27(1): 53-66. https ://doi .org/10.161 5/CritRevPhysRehabilMed. 2015011760

[45] Courneya KS, Friedenreich CM. Utility of the Theory of Planned Behavior for understanding exercise during breast cancer treatment. Psycho-oncol. 1999; 8(2): 112-122. https: //doi.org/10.1002/(SICI) 1099-1611(199903/04)8: 2<112: :AID-PON341>3.0.CO;2-L 